\title{
Analysis of Fungal Spore Mycotoxin and the Relationship Between Spore Surface Area and Mycotoxin Content Utilizing a Protein Translation Inhi- bition Assay
}

\author{
Timothy R. Dean ${ }^{*},, \mathrm{a}$, Jonathan A. Black ${ }^{\S b}$, Karin Foarde ${ }^{\mathrm{b}}$ and Marc Menetrez ${ }^{\mathrm{a}}$ \\ ${ }^{a}$ National Risk Management Research Laboratory, U.S. Environmental Protection Agency, 109 T.W. Alexander Drive, \\ Research Triangle Park, NC 27711, USA \\ ${ }^{b}$ Microbiology and Molecular Biology Department, RTI International, 3040 Cornwallis Road, Research Triangle Park, \\ NC 27709
}

\begin{abstract}
Due to mounting evidence suggesting that biological contamination in the built environment may cause a myriad of adverse health effects, research aimed at understanding the potential exposure to fungal organisms and their metabolites is of utmost importance. To this end we utilized a protein translation inhibition assay to determine the relative amounts of mycotoxin present in various fungal spore preparations. Basing our results on the transformation of firefly luciferase in a rabbit reticulocyte system our initial data showed that spores from different fungal genera contained varying amounts of mycotoxins. However, by calculating the surface area of the spores and then normalizing the assay by keeping surface areas equivalent we determined that there is a direct relationship between spore size and mycotoxin content. This is an important finding because simply knowing the numbers of spores is clearly not sufficient; one needs to know the specific species present to formulate an effective risk assessment and remediation regimen. This work illuminates the potential inhalation exposure to trichothecene mycotoxins that are suspended in the air of the indoor environment. Currently many methods of fungal analysis in the indoor environment are simply based on spore counts. Our analysis clearly demonstrates that it is equally important to know the species of organisms present to accurately determine potential exposure to mycotoxins, thereby enabling effective risk management decisions to be made.
\end{abstract}

Keywords: Trichothecene, mycotoxin, translational inhibition, T2 toxin, Stachybotrys chartarum.

\section{INTRODUCTION}

It has been estimated that humans spend between $80-$ $90 \%$ of their time in the indoor environment $[1,2]$. With such a large portion of time spent in the built environment it is accepted that a significant portion of unhealthy personal exposure to airborne contaminants can take place indoors [2]. A substantial factor that can adversely affect the quality of the indoor environment is biological contamination, mainly by the filamentous fungi (mold). Estimates of fungal contamination of homes in North America indicate that up to $40 \%$ contain mold growth, while in other parts of the world such as Northern Europe the proportion of fungal contaminated homes ranges between 20-40\% [3, 4]. The presence of fungal organisms in homes and offices may play a major role in what is being called "Sick Building Syndrome" [5].

Recently, Mudarri and Fisk utilized asthma as an endpoint to determine the economic impact of dampness and mold in the United States. Roughly twenty two million people are reported to have asthma in the United States with approximately 4.6 million cases projected to be linked to mold exposure in the indoor environment [6]. Their findings

\footnotetext{
*Address correspondence to this author at the National Risk Management Research Laboratory, U.S. Environmental Protection Agency, 109 T.W. Alexander Drive, Research Triangle Park, NC 27711, USA; Tel: (919) 5412304; Fax: (919) 541-2157; E-mail: dean.timothy@epa.gov

${ }^{\S} \mathrm{TD}$ and JB are co-first authors.
}

show that the national annual cost of asthma that is caused by dampness and mold exposure in the built environment is estimated to be approximately $\$ 3.5$ billion [6]. This analysis makes it clear that dampness and mold in the indoor environment poses considerable health risks as well as sizeable economic costs.

In addition to asthma, there are severe health effects attributed to the filamentous fungi like idiopathic pulmonary hemosiderosis (IPH) in infants resulting in death and other health effects including itchy eyes, stuffy nose, fatigue, and headache [7-15]. One route of exposure is by inhalation of fungal organisms which may cause either allergic infectious or toxic effects depending on the species, the length of exposure, and the strength of the immune system of the exposed individual. Toxic effects can also be induced by the presence of certain secondary metabolites commonly referred to as mycotoxins. Secondary metabolites are products that are not required in normal cellular metabolism, however, they provide a competitive advantage when growing in the presence of other competing organisms.

Fungal secondary metabolites that have been shown to cause adverse health impacts are the trichothecene mycotoxins. The trichothecenes are low molecular weight $(<1 \mathrm{kDa})$ products that are produced by a wide range of fungal organisms including Stachybotrys, Fusarium, Myrothecium, Trichoderma, as well as two plant species $[16,17]$. Trichothecenes are in the sesquiterpenoid family of natural products and are known to be potent inhibitors of eukaryotic pro- 
tein synthesis [17]. Trichothecenes have been shown to be present in both the conidia as well as the spores of producing fungal organisms [18].

Airborne spores and spore fragments contain trichothecene mycotoxins that can result in exposure via inhalation by individuals [19]. While there is consensus that inhalation exposure to molds can cause adverse health effects there are factors that cannot be quantified. Schulz et al. concluded that there is a health hazard due to toxic effects after the inhalation of high concentrations of spores from the filamentous fungi [20]. It has also been known for some time that toxins produced by Stachybotrys chartarum can accumulate to very high levels in the conidia and that spores laden with toxins can affect lung function $[21,22,23]$. However, the role that mycotoxins have in the manifestation of the aforementioned ailments is currently unknown, and studies aimed at mycotoxin inhalation exposure are lacking.

Due to the increasing evidence that suggests that the filamentous fungi may play a major role in sick building syndrome we utilized a protein translation assay to determine the relative amounts of toxin present in various spore preparations. The purpose of this study was to utilize a standard in vitro toxicity assay to compare the relative amounts of toxin present in various fungal spore preparations to T2 toxin. The comparison of the toxicity to $\mathrm{T} 2$ toxin was done explicitly to provide a reference point for individual spore preparation toxicity. In this manuscript we present data that suggest that simply knowing the identity of the fungal organisms airborne in the indoor environment is not a complete picture and equally important are the number and size of spores in determining the potential for mycotoxin exposure.

\section{MATERIALS AND METHODS}

\section{Materials and Reagents}

Lyophilized T-2 trichothecene mycotoxin used as a positive control in the luciferase translation assay was purchased from Sigma, St. Louis, Mo. The Rabbit Reticulocyte Lysate Kit and Steady Bright-Glo Reagent were purchased from Promega, Madison, WI. Steady Bright-Glo Reagent was divided into $0.5 \mathrm{~mL}$ aliquots, and all reagents were stored in the dark at $-70{ }^{\circ} \mathrm{C}$ until needed.

\section{Preparation and Storage of T-2 Toxin}

Lyophilized stock of T-2 toxin was suspended in 95\% ethanol to ensure complete solubility and subsequently diluted in cold deionized sterile $18-\mathrm{Mohm}$ water $\left(\mathrm{dH}_{2} \mathrm{O}\right)$ at specific concentrations for easy use in the translation assay. The final concentration of ethanol in the $\mathrm{T}-2$ preparations was below $0.01 \%$ in the translation reaction mixture. $\mathrm{T}-2$ toxin suspensions stored at $-70{ }^{\circ} \mathrm{C}$ for greater than 30 days exhibited no loss of toxicity.

\section{Fungi Growth Conditions}

The following media and fungi were used in this study: Potato Carrot Agar (laboratory (RTI) prepared) for Alternaria alternata; Sabouraud Dextrose (Difco) for Aspergillus fumigatus, Aspergillus versicolor strains 3097, 3182, 3236, 3332, 3348, 3418, and 3843, Penicillium brevicompactum, Penicillium chyrsogenum; Malt Extract Agar (Oxoid) for Cladosporium, Stachybotrys chartarum strains 5108, 5111, 5802, 5806, 6307, Houston; Potato Dextrose Agar (Difco) for Fusarium oxysporum. A. versicolor and S. chartarum strains were isolated from house dust samples from homes in Cleveland, Ohio. The numbers following the organism name are the laboratory identification numbers. All strain numbers are RTI laboratory identification numbers. All cultures were incubated in a temperature-controlled $\left(21 \pm 3{ }^{\circ} \mathrm{C}\right)$, HEPA (High Efficiency Particulate Absolute) filtered room.

\section{Preparation of Mycotoxins}

Spores and conidia of each organism were collected by gently rolling a wetted sterile calcium alginate swab over confluent fungal growth and immersing the spore covered swab in cold $\mathrm{dH}_{2} \mathrm{O}$. This preparation was immediately washed once with $200 \mu \mathrm{L}$ of cold $\mathrm{dH}_{2} \mathrm{O}$ and pelleted at 1,800 $g$ for 1 min. The pellet was suspended in cold $\mathrm{dH}_{2} \mathrm{O}$ and spore integrity and purity was assessed by light microscopy and quantitated by hemacytometer. $100 \mu \mathrm{L}$ of spore suspension was pipetted into a thin-walled PCR tube filled with approximately $100 \mu \mathrm{L}$ of $0.1 \mathrm{~mm}$ glass beads. The tubes were capped and subjected to milling in a bead beater (Biospec Products, Bartlesville, OK) on high for 30 seconds, paused for 30 seconds, and milled for an additional $30 \mathrm{sec}-$ onds. The cellular debris was pelleted, and the supernatant was passed through Ultrafree-MC 5000 NMWL microcentrifuge filter (Millipore Corp, Bedford, MA) at 1,800 g for 25 min to remove small interfering proteins and RNases [24]. The filtrate was evaporated to near dryness at $65{ }^{\circ} \mathrm{C}$ for 25 minutes in a Speed Vac Plus centrifuge (Savant Instrument, Farmingdale, NY). At no time did the sample dry completely. Extracts reconstituted in $10 \mu \mathrm{L}$ of $\mathrm{dH}_{2} \mathrm{O}$ were stored at $-70{ }^{\circ} \mathrm{C}$ until needed.

\section{Spore Equivalents by Surface Area}

All spores and conidia were equated by surface area using published width and length dimensions [25] using the following equations:

Surface area of a sphere for Aspergillus $(\mathrm{r}=1.5)$ and Penicillium $(\mathrm{r}=2)$;

$S=4 \pi r^{2}$

Surface area of a prolate ellipsoid for Alternaria $(a=30$, $\mathrm{b}=50)$, Cladosporium $(\mathrm{a}=10, \mathrm{~b}=2.5)$, Stachybotrys $(\mathrm{a}=12$, $\mathrm{b}=3$ );

$S_{p e}=2 \pi b^{2}(1+(a \div b) \arcsin (e) \div e)$

where $e=\operatorname{sqrt}\left(a^{2}-b^{2}\right) \div a(2)$

Surface area of (2) cylinders for Fusarium $(\mathrm{r}=2.5, \mathrm{~h}=5)$.

$S_{c}=\left(2 \pi r^{2}+2 \pi r h\right) \times 2$

Using these equations we determined surface areas, equivalents, and spore equivalents for extraction as outlined in Table 1.

\section{In Vitro Luminescence Protein Translation}

The translation of firefly luciferase mRNA was carried out as previously described [24] with minor modifications. A master mix of the translation reaction was made by combining $8.75 \mu \mathrm{L}$ Flexi Rabbit Reticulocyte Lysate, $0.25 \mu \mathrm{L}$ Complete Amino Acid Mixture ( $1 \mathrm{mM}), 0.35 \mu \mathrm{L}$ Potassium Chloride $(2.5 \mathrm{M}), 0.25 \mu \mathrm{L}$ RNA substrate (omitted for negative control), and nuclease-free water to a final volume of 12.5 $\mu \mathrm{L}$ for each reaction. The luciferase protein translation assay 
was performed by combining $1.0 \mu \mathrm{L}$ of the extracts to master mix with RNA substrate to a final volume of $12.5 \mu \mathrm{L}$ in a PCR tube. The reaction tubes were placed in a thermal cycler (BioRad, Hercules, CA) programmed for a single cycle of 90 min at $30{ }^{\circ} \mathrm{C}$. The samples were removed from the thermal cycler within 5 min of completion and either used immediately or stored at $-70^{\circ} \mathrm{C}$ to be used within $24 \mathrm{~h}$.

Table 1. Calculated Surface Area and Spore Equivalents for Each Organism Used in this Study

\begin{tabular}{|l|c|c|c|}
\hline \multicolumn{1}{|c|}{ Organism } & $\begin{array}{c}\text { Surface } \\
\text { Area }\end{array}$ & Equivalents & $\begin{array}{c}\text { Spore } \\
\text { Equivalents }\end{array}$ \\
\hline \hline Alternaria spp. & 1564.16 & 1.00 & $1.00 \times 10^{6}$ \\
\hline Aspergillus spp. & 28.26 & 55.35 & $5.53 \times 10^{7}$ \\
\hline Cladosporium spp. & 267.16 & 5.85 & $5.85 \times 10^{6}$ \\
\hline Fusarium spp. & 235.50 & 6.64 & $6.64 \times 10^{6}$ \\
\hline Penicillium spp. & 50.24 & 31.13 & $3.11 \times 10^{7}$ \\
\hline Stachybotrys spp. & 384.72 & 4.07 & $4.07 \times 10^{6}$ \\
\hline
\end{tabular}

\section{Luciferase Activity Assay}

An aliquot of Steady Bright-Glo Reagent was thawed slowly to room temperature by placing the tube in a small beaker of water in the dark $30 \mathrm{~min}$ before the start of the activity assay. The Steady Bright-Glo Reagent $(25 \mu \mathrm{L})$ was pipetted into test wells of a Costar 96 well $1 / 2$ volume white polystyrene plate (Corning Inc., Corning, NY). Each assay sample $(2.5 \mu \mathrm{L})$ was added by pipette and mixed in by swirling the pipette tip in a circular motion 3-5 times. Pipette mixing of the mixture was not done to reduce the generation of interfering foaming. The plate was covered by a foil-lined lid and was either read within $10 \mathrm{~min}$ or stored for up to $2 \mathrm{~h}$ in the dark without loss of activity. The foil was removed and the plate was read in a Tecan GENios (Tecan U.S., RTP, NC) using luminescence mode and XFLUOR4 software. The activity of all samples was expressed as percent control (water added in place of toxin or extract). Control samples with luciferase mRNA and no toxin added consistently yielded about 400,000 RLU for $100 \%$ luciferase mRNA translation.

\section{RESULTS}

\section{Protein Translation Inhibition Utilizing $1 \times 10^{6}$ Fungal Spores}

Initial assay conditions were developed to determine the amount of translation inhibition utilizing $1 \times 10^{6}$ spores of each of the organisms, and making a direct comparison to T2 toxin. T2 toxin is considered one of the most toxic of the trichothecenes, is highly characterized with strong inhibition of protein synthesis, and has been previously used as a positive control in the development of this assay [26]. Fig. (1) shows that although all the extracts had some inhibition on the translation of firefly luciferase, the A. alternata, the six Stachybotrys isolates, and C. cladosporoides all inhibit translation at levels approximately 2.5 to 6 times greater than the Aspergillus, Penicillium, or Fusarium species tested.

When the values presented in Fig. (1) are compared to the standard curve developed utilizing purified T2 toxin (data not shown) direct comparisons were made and we obtained T2 equivalents (Table 2). The data revealed that $A$. alternata inhibited protein synthesis to a much greater extent than even $250 \mathrm{ng}$ of T2 toxin. The trichothecenes produced by the various $S$. chartarum strains assayed ranged from 28.3 ng to $90 \mathrm{ng}$ T2 toxin equivalent inhibition. C. cladosporoides and $S$. chartarum (Houston) were nearly equal at approximately $28 \mathrm{ng}$ of T2 toxin equivalents. At the other end of the spectrum were the Aspergillus, Penicillium, and Fusarium species which all produced less than $5.0 \mathrm{ng}$ T2 equivalents inhibition within this assay.

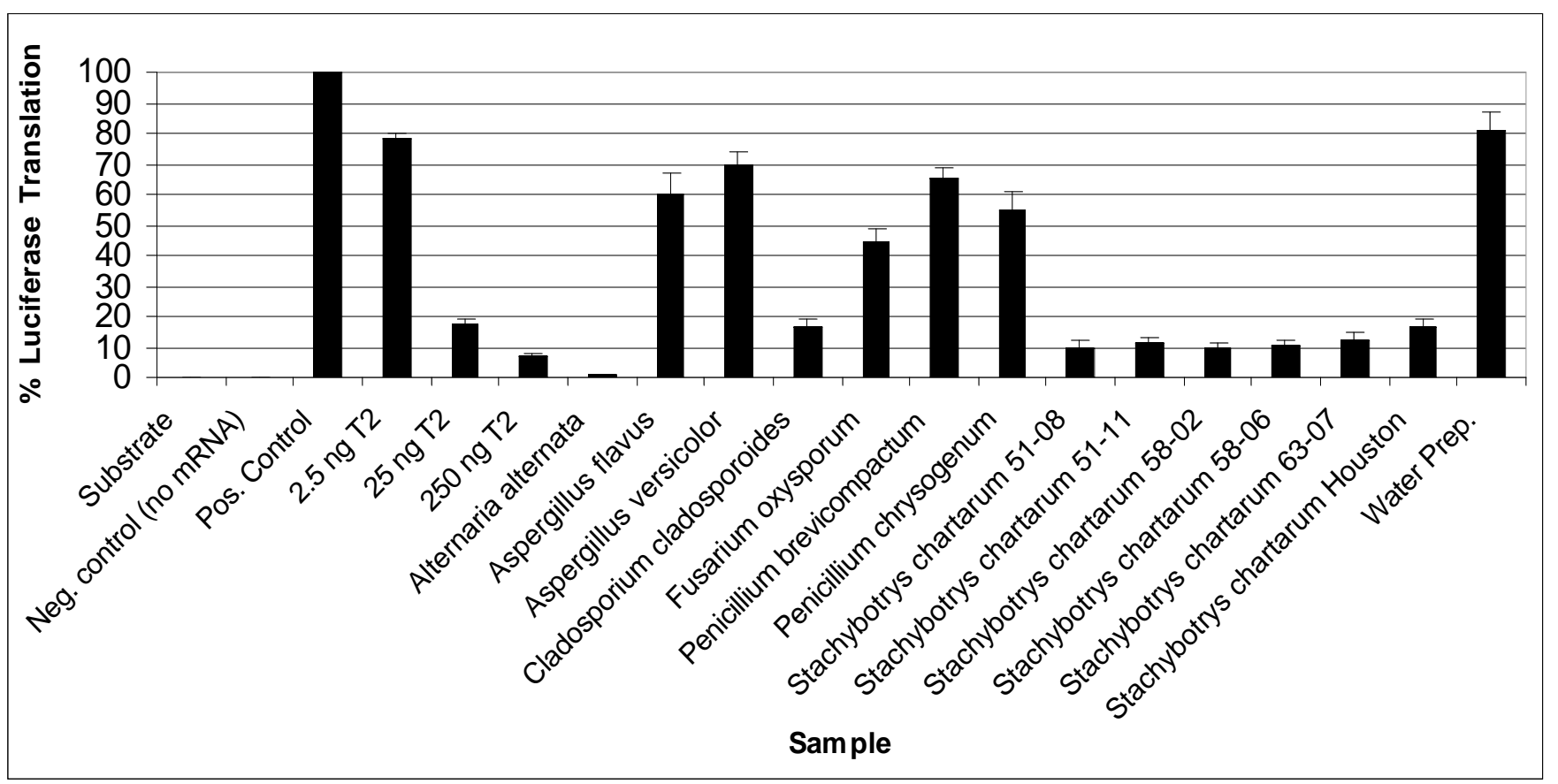

Fig. (1). Translational inhibition of firefly luciferase by fungal organisms used in this study including titrated amounts of T2 toxin. 
Table 2. Percent Translation and Calculated T2 Equivalents for Study Organisms

\begin{tabular}{|l|c|c|}
\hline \multicolumn{1}{|c|}{ Organism } & \% Translation & T2 Equivalents \\
\hline \hline 2.5 ng T2 & 77.85 & 2.5 \\
\hline Aspergillus versicolor & 69.61 & 2.9 \\
\hline Penicillium brevicompactum & 65.62 & 3.05 \\
\hline Aspergillus flavus & 60.02 & 3.4 \\
\hline Penicllium chrysogenum & 55.1 & 3.9 \\
\hline Fusarium oxysporum & 44.66 & 4.5 \\
\hline 25 ng T2 & 17.49 & 25 \\
\hline Cladosporium cladosporoides & 16.73 & 28 \\
\hline Stachybotrys chartarum Houston & 16.44 & 28.3 \\
\hline Stachybotrys chartarum 63-07 & 12.06 & 55 \\
\hline Stachybotrys chartarum 51-11 & 11.39 & 62 \\
\hline Stachybotrys chartarum 58-06 & 10.85 & 70 \\
\hline Stachybotrys chartarum 58-02 & 9.87 & 83 \\
\hline Stachybotrys chartarum 51-08 & 9.78 & 90 \\
\hline 250 ng T2 & 6.57 & 250 \\
\hline Alternaria alternata & 0.69 & BDL \\
\hline
\end{tabular}

\section{Calculation of Spore Surface Areas}

Following the initial set of experiments the fungal species with larger spore sizes seemed to inhibit protein synthesis to a much greater extent than the species with smaller sized spores. With this observation in mind we set out to utilize geometric calculations of spore surface area and then repeat the assay with equivalent spore surface areas in each assay. According to these calculations A. alternata had the largest surface area at $1564.16 \mathrm{~nm}^{2}$ followed by the $S$. chartarum strains at $384.72 \mathrm{~nm}^{2}$. C. cladosporoides had a surface area of $267.16 \mathrm{~nm}^{2}$ while the surface areas for the Penicillium and Aspergillus species were just $50.24 \mathrm{~nm}^{2}$ and 28.26 $\mathrm{nm}^{2}$, respectively. $F$. oxysporum gave a calculated surface area of $235.50 \mathrm{~nm}^{2}$.

\section{Protein Translation Inhibition Following Normalization of Spore Surface Area}

We reasoned that because A. alternata had the largest spores as well as the highest translation inhibition at $1 \times 10^{6}$ spores that all subsequent assays should be completed with a total surface area equal to $1 \times 10^{6} \mathrm{~A}$. alternata spores (Table 1). Using these surface areas we obtained rather extraordinary results in the translation inhibition assay (Fig. 2). When the assays were run with spore surface areas equivalent to $A$. alternata the results were very uniform with translation inhibition ranging from $95.38 \%$ for P. brevicompactum to $99 \%$ for $A$. alternata. Among the $S$. chartarum isolates that were tested, the Houston strain once again showed slightly less translation inhibition at $97.8 \%$ compared to the other strains which gave approximately $99 \%$ inhibition.

\section{Translation Inhibition for Aspergillus Versicolor Isolates}

Asp. versicolor is commonly found in unhealthy indoor environments and studies have shown that inhalation exposure to Asp. versicolor spores may cause acute inflammation and cytotoxic effects $[27,28]$. To this end we analyzed seven different Asp. versicolor isolates for their ability to inhibit protein synthesis focusing on potential strain differences. The data presented in Fig. (3) indicated that, while not substantial, there were definitely differences in the amount of translational inhibition. Asp. versicolor strain \# 3332 showed

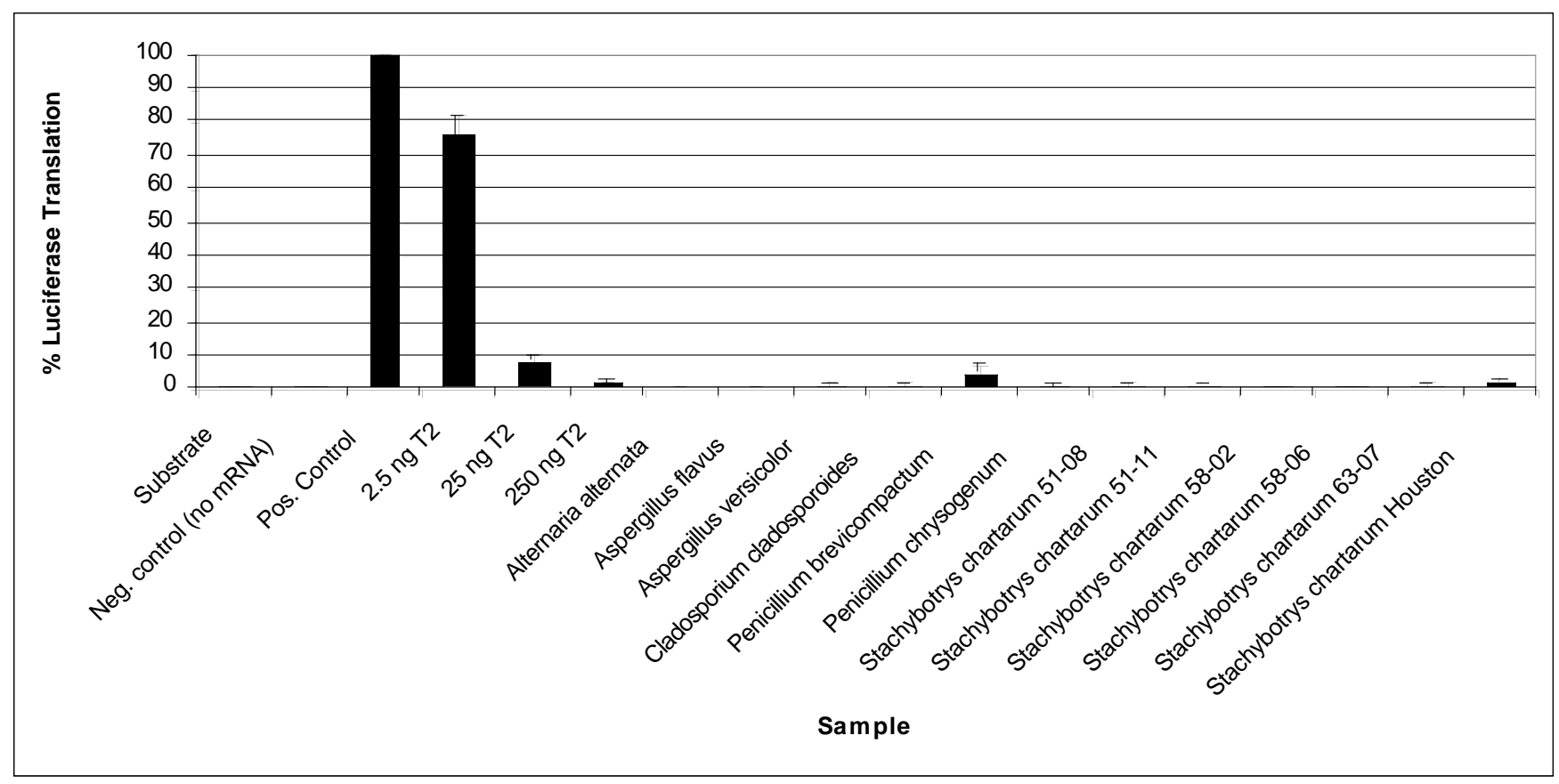

Fig. (2). Translational inhibition of firefly luciferase by fungal organisms used in this study with all assays normalized to $1 \mathrm{X} 10^{6}$ spores of A. alternata. 


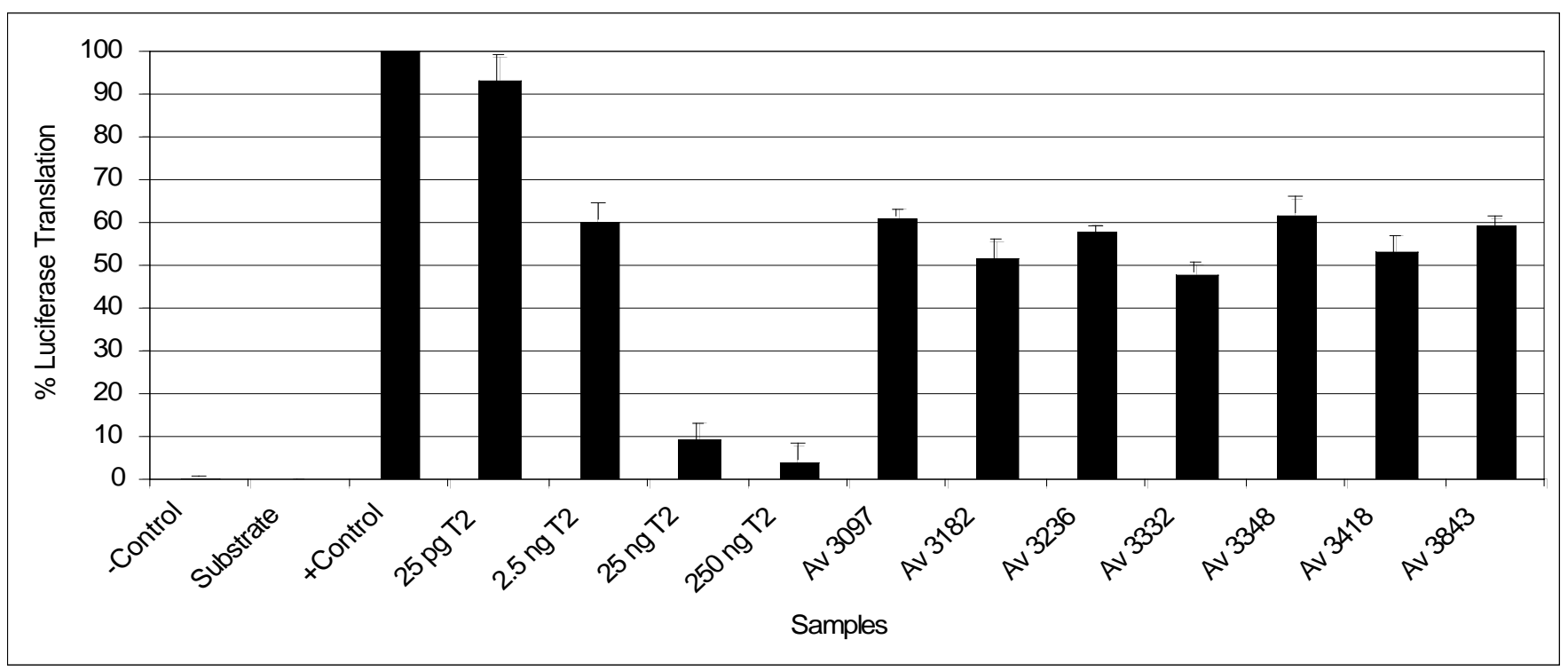

Fig. (3). Translational inhibition of firefly luciferase by various strains of A. versicolor.

the greatest amount of inhibition while Asp. versicolor strain \# 3348 showed the least. Minor differences were observed between the rest of the Aspergillus strains used for this study.

\section{DISCUSSION}

This work was performed to shed additional light on the potential inhalation exposure to trichothecene mycotoxins that are associated with, and carried by fungal spores suspended in the air of the built environment. The organisms used in this study were chosen based on their prevalence in the indoor environment and specifically those environments with known fungal contamination [9]. Continuing research may show that many of these organisms function as signature species that are present in unhealthy indoor environments.

One of the known cytotoxic effects caused by the macrocyclic trichothecenes is their potent inhibition of protein synthesis [17]. We utilized this function to assay the ability of various spore preparations to reduce or inhibit protein synthesis in an in vitro luminescence protein translation model. Because the trichothecene mycotoxin, T2, is considered one of the most toxic trichothecenes [29] and is highly characterized, the results of our translation inhibition assay were compared to $\mathrm{T} 2$ for comparative analysis.

Prior research has shown that T2 acts by blocking protein synthesis at initiation with a stoichiometry for T2:ribosome binding 1:1 [30]. There has been no evidence that $\mathrm{T} 2$ has catalytic capabilities, therefore translation inhibition is carried out by steric interference [30]. By utilizing this assay we not only assayed for the presence of the toxins in the spores, but we also assayed for biologically active molecules. However, by utilizing this assay and comparing the results to the T2 toxin there is a good possibility that there is an understatement of the actual biological effect. Research has shown that the T2 toxin has a much greater cytotoxic effect in a "whole cell" as opposed to a "free cell" system [31]. Our assay detects the ability of the toxin to inhibit protein synthesis. However, it does not take into account the toxin's ability to disrupt other cellular function such as causing breaks in single stranded DNA, disruption of polysomes, or binding to sulfhydryl enzymes [31]. Nevertheless, this assay is fully capable of determining the relative amounts of toxin associated with the different fungal spores tested.

Not surprisingly, our initial experiments showed that different fungal organisms contained different quantities of mycotoxins. Upon realization that the larger the spore the greater the translational inhibition, we constructed a simple geometric approach that allowed for each assay to contain spore surface area equivalents. Following this analysis there appears to be a direct relationship between spore size and translational inhibition. When surface areas were equal there was uniform translational inhibition, within the sensitivity of this assay. It appears that larger spores are able to accommodate greater amounts of toxin making a single larger spore more toxic than a smaller spore, assuming of course the same toxin is present and all other things are equal.

Within our assay analysis of various Asp. versicolor isolates showed slight variation in the amount of translational inhibition. This result is important because it demonstrates the potential variability in the presence of spore bound mycotoxin even within isolates of the same species. It should also be noted that this same trend was observed in the $S$. chartarum strains that were tested.

This analysis holds great importance for the sampling and analysis of fungal contaminated indoor environments. Traditional methods of air sampling include impacting spores and fungal fragments on glass surfaces and simply counting spores and making calculations on the number of spores per cubic meter of air. Knowing now that the amount of mycotoxin present may be directly related to spore size, simply counting the total number of spores does not accurately reflect the potential exposure to mycotoxins. To accurately reflect mycotoxin exposure there needs to be speciation as well as quantification of each species within the fungal community. This analysis lends credence to the need to both improve our ability to identify as well as quantify fun- 
gal organisms within the built environment in order to accurately predict potential exposure.

\section{REFERENCES}

[1] Simoni M, Jaakkola MS, Carrozzi L, Baldacci S, Di Pede F, Viegi G. Indoor air pollution and respiratory health in the elderly. Eur Respir J Suppl 2003; 40: 15s-20s.

[2] Long CM, Suh HH, Kobzik L, Catalano PJ, Ning YY, Koutrakis P. A pilot investigation of the relative toxicity of indoor and outdoor fine particles: in vitro effects of endotoxin and other particulate properties. Environ Health Perspect 2001; 109(10): 1019-26.

[3] Brunekreef B, Dockery DW, Speizer FE, Ware JH, Spengler JD, Ferris BG. Home dampness and respiratory morbidity in children. Am Rev Respir Dis 1989; 140(5): 1363-7.

[4] Nielsen FK. Mycotoxin production by indoor molds. Fungal Genet Biol 2003; 39(2): 103-17.

[5] De-Wei LaY CS. Sick Building Syndrome. San Diego, California: Elsevier Academic Press; 2004. (Fungal Contamination as a major contributor to sick building syndrom).

[6] Mudarri D, Fisk WJ. Public health and economic impact of dampness and mold. Indoor Air 2007; 17(3): 226-35.

[7] Meklin T, Haugland RA, Reponen T, et al. Quantitative PCR analysis of house dust can reveal abnormal mold conditions. J Environ Monit 2004; 6(7): 615-20.

[8] Vesper S, Dearborn DG, Yike I, et al. Evaluation of Stachybotrys chartarum in the house of an infant with pulmonary hemorrhage: quantitative assessment before, during, and after remediation. J Urban Health 2000; 77(1): 68-85.

[9] Vesper SJ, Varma M, Wymer LJ, Dearborn DG, Sobolewski J, Haugland RA. Quantitative polymerase chain reaction analysis of fungi in dust from homes of infants who developed idiopathic pulmonary hemorrhaging. J Occup Environ Med 2004; 46(6): 596601.

[10] Andersen B, Nielsen KF, Jarvis BB. Characterization of Stachybotrys from water-damaged buildings based on morphology, growth, and metabolite production. Mycologia 2002; 94: 392-403.

[11] Etzel RA. Stachybotrys. Curr Opin Pediatr 2003; 15(1): 103-6.

[12] Kuhn DM, Ghannoum MA. Indoor mold, toxigenic fungi, and Stachybotrys chartarum: infectious disease perspective. Clin Microbiol Rev 2003; 16(1): 144-72.

[13] Dearborn DG, Yike I, Sorenson WG, Miller MJ, Etzel RA. Overview of investigations into pulmonary hemorrhage among infants in Cleveland, Ohio. Environ Health Perspect 1999; 107(Suppl 3): 495-9.

[14] Mahmoudi M, Gershwin ME. Sick building syndrome. III. Stachybotrys chartarum. J Asthma 2000; 37(2): 191-8.

[15] Gent JF, Ren P, Belanger K, et al. Levels of household mold associated with respiratory symptoms in the first year of life in a cohort at risk for asthma. Environ Health Perspect 2002; 110(12): A781-6.

[16] Jarvis BB, Miller JD. Mycotoxins as harmful indoor air contaminants. Appl Microbiol Biotechnol 2005; 66(4): 367-72.
[17] Brown DW, McCormick SP, Alexander NJ, Proctor RH, Desjardins AE. A genetic and biochemical approach to study trichothecene diversity in Fusarium sporotrichioides and Fusarium graminearum. Fungal Genet Biol 2001; 32(2): 121-33.

[18] Gregory L, Pestka JJ, Dearborn DG, Rand TG. Localization of satratoxin-G in Stachybotrys chartarum spores and spore-impacted mouse lung using immunocytochemistry. Toxicol Pathol 2004; 32(1): 26-34.

[19] Brasel TL, Martin JM, Carriker CG, Wilson SC, Straus DC. Detection of airborne Stachybotrys chartarum macrocyclic trichothecene mycotoxins in the indoor environment. Appl Environ Microbiol 2005; 71(11): 7376-88.

[20] Schultz T, Senkpiel K, Ohgke H. Comparison of the toxicity of reference mycotoxins and spore extracts of common indoor moulds. Int J Hyg Environ Health 2004; 207: 267-77.

[21] Sorenson WG, Frazer DG, Jarvis BB, Simpson J, Robinson VA. Trichothecene mycotoxins in aerosolized conidia of Stachybotrys atra. Appl Environ Microbiol 1987; 53(6): 1370-5.

[22] Mason CD, Rand TG, Oulton M, MacDonald JM, Scott JE. Effects of Stachybotrys chartarum (atra) conidia and isolated toxin on lung surfactant production and homeostasis. Nat Toxins 1998; 6(1): 2733.

[23] Nikulin M, Reijula K, Jarvis BB, Hintikka EL. Experimental lung mycotoxicosis in mice induced by Stachybotrys atra. Int J Exp Pathol 1996; 77(5): 213-8.

[24] Yike I, Allan T, Sorenson WG, Dearborn DG. Highly sensitive protein translation assay for trichothecene toxicity in airborne particulates: comparison with cytotoxicity assays. Appl Environ Microbiol 1999; 65(1): 88-94.

[25] Samson RA, Hoekstra ES, Frisvad JC. Introduction to food and airborne fungi. $6^{\text {th }}$ ed. Utrecht, Netherlands: Centraalbureau voor Schimmelcultures; 2000

[26] Black JA, Foarde KK, Menetrez MY. Solvent comparison in the isolation, solubilization, and toxicity of Stachybotrys chartarum spore trichothecene mycotoxins in an established in vitro luminescence protein translation inhibition assay. J Microbiol Methods 2006; 66(2): 354-61.

[27] Jussila J, Komulainen H, Kosma VM, Nevalainen A, Pelkonen J, Hirvonen MR. Spores of Aspergillus versicolor isolated from indoor air of a moisture-damaged building provoke acute inflammation in mouse lungs. Inhal Toxicol 2002; 14(12): 1261-77.

[28] Korpi A, Kasanen JP, Raunio P, Pasanen AL. Acute effects of Aspergillus versicolor aerosols on murine airways. Indoor Air 2003; 13(3): 260-6.

[29] Hussein HS, Brasel JM. Toxicity, metabolism, and impact of mycotoxins on humans and animals. Toxicology 2001; 167(2): 10134.

[30] Middlebrook JL, Leatherman DL. Binding of T-2 toxin to eukaryotic cell ribosomes. Biochem Pharmacol 1989; 38(18): 3103-10.

[31] Khachatourians GG. Metabolic effects of trichothecene T-2 toxin. Can J Physiol Pharmacol 1989; 68: 1004-8..

(C) Dean et al.; Licensee Bentham Open.

This is an open access article distributed under the terms of the Creative Commons Attribution License (http://creativecommons.org/licenses/by/2.5/), which permits unrestrictive use, distribution, and reproduction in any medium, provided the original work is properly cited. 